\title{
De um trabalhador de saúde mental para muitos outros: sacrifício e sacralização em tempos de covid
}

\author{
De un trabajador de salud a muchos: sacrificio y sacralización en tiempos de covid
}

\author{
From one health worker to many: sacrifice and sacralization in times of covid
}

\author{
Helen Barbosa dos Santos \\ Universidade Federal do Rio Grande do Sul (UFRGS), Porto Alegre - RS/Brasil \\ ORCID: 0000-0002-7732-3647 \\ E-mail: helenpsi@yahoo.com.br
}

Fernanda Marques Paz

Centro Universitário Cenecista de Osório (UNICNEC), Osório - RS/Brasil ORCID: 0000-0003-3364-2635

E-mail: 1905.fernandapaz@cnec.br

Fabio Dal Molin

Universidade Federal do Rio Grande do Sul (UFRGS), Porto Alegre - RS/Brasil ORCID: 0000-0001-6291-6098

E-mail: lexpartelab@gmail.com

\begin{abstract}
Resumo
O relato de experiência busca analisar, sobre a perspectiva de duas profissionais de saúde mental do Sistema Único de Saúde (SUS), a dimensão sacrificial do trabalhador de saúde no contexto de pandemia por COVID 19, nos meses de junho de 2020 há março de 2021. As reflexões iniciais emergem sobre o processo de trabalho em um Centro de Atenção Psicossocial (CAPS). A experiência nesse serviço de média complexidade revela as angústias produzidas diante do poder decisório da gestão municipal de saúde, especialmente, relativas à impossibilidade do trabalho remoto. Em um segundo momento, as reflexões sobre as problemáticas especificadas revelam o panorama nacional de um governo de extremadireita que reitera a lógica sacrificial que emerge em meio à pandemia. Para tanto, são utilizados os conceitos de dispositivos de poder de Michel Foucault e Homo Sacer de Giorgio Agambem. É percebida, assim, a indissociabilidade entre a dimensão microssocial e macrossocial das problemáticas apresentadas, bem como colocado em questão o termo "linha de frente" a fim de interseccionar o sofrimento de profissionais de serviços hospitalares com a de outros profissionais de saúde da rede SUS, em dispositivos de média complexidade. Conclui-se que a dimensão sacrificial que produz subjetivamente o profissional de saúde do SUS sustenta um estado de exceção que em última instância, ao sacralizar os 'verdadeiros heróis' também os expõe, tanto ao risco desnecessário de contágio, como nas decisões de fazer viver e deixar morrer.
\end{abstract}

Palavras-chaves: Saúde do trabalhador; Saúde mental; Pandemia; Trabalho remoto.

\section{Resumen}

El informe de experiencia busca analizar, desde la perspectiva de dos profesionales de la salud mental del Sistema Único de Salud (SUS), la dimensión sacrificial del trabajador de salud en el contexto de la pandemia de COVID 19, de junio de 2020 a marzo de 2021. Surgen las primeras reflexiones sobre el proceso de trabajo en un Centro de Atención Psicosocial (CAPS). La experiencia en este servicio de mediana complejidad revela las inquietudes que produce el poder de decisión de la gestión municipal de salud, especialmente en cuanto a la imposibilidad del trabajo a distancia. En segundo lugar, las reflexiones sobre temas específicos revelan el panorama nacional de un gobierno de extrema derecha que reitera la lógica sacrificial que emerge en medio de la pandemia. Por tanto, se utilizan los conceptos de dispositivos de potencia de Michel Foucault y Homo Sacer de Giorgio Agambem. Así, se percibe la inseparabilidad entre las dimensiones microsocial y macrosocial de los problemas presentados y se cuestiona el término "primera línea" para cruzar el sufrimiento de los profesionales de los servicios hospitalarios con el de otros profesionales de la salud de la red del SUS, en dispositivos de mediana complejidad. Se concluye que la dimensión sacrificial que produce subjetivamente el profesional de la salud del SUS sustenta un estado de 
excepción que, en definitiva, al sacralizar a los 'verdaderos héroes' también los expone, tanto al riesgo innecesario de contagio como en las decisiones de ganarse la vida y dejarlo morir.

Palabras clave: Salud del trabajador; Salud mental; Pandemia; Trabajo remoto.

\begin{abstract}
The experience report seeks to analyze, from the perspective of two mental health professionals from the Unified Health System (SUS), the sacrificial dimension of the health worker in the context of the COVID 19 pandemic, from June 2020 to March 2021 Initial reflections emerge about the work process in a Psychosocial Care Center (CAPS). The experience in this medium-complexity service reveals the anxieties produced by the decision-making power of the municipal health management, especially regarding the impossibility of remote work. In a second moment,
\end{abstract}

\section{Introdução}

Este estudo parte dos tensionamentos produzidos pelo processo de trabalho de equipe multidisciplinar ${ }^{1}$ em um serviço de Centro de Atenção Psicossocial (CAPS) ${ }^{2}$ em município de do Rio Grande do Sul através das reflexões de duas profissionais de saúde mental. O objetivo deste escrito foi analisar a produção as valorações morais produzidas pela equipe de trabalho em tempos de pandemia por COVID 19 a partir das reinvindicações de alguns profissionais de saúde, como assistentes socias, psicólogos e estagiários de psicologia pelo trabalho remoto aos usuários de saúde em situações de menor gravidade. Este objetivo inicial nos leva em direção à problematização epistemológica de autores das ciências sociais que dimensionam os processos de sacralização e sacrífico dos profissionais de saúde.

\footnotetext{
${ }^{1}$ Metade da equipe é constituída por profissionais da psicologia. Demais técnicos são assistentes socias, psiquiatras, terapeuta ocupacional e enfermeira, bem como profissionais da equipe administrativa, cozinha, serviços gerais e vigilante.

2 Os Centros de Atenção Psicossocial (CAPS) são unidades especializadas em saúde mental para tratamento e reinserção social de pessoas com transtorno mental grave e persistente. Os centros oferecem um atendimento interdisciplinar, composto por uma equipe
}

reflections on specific issues reveal the national panorama of an extreme right-wing government that reiterates the sacrificial logic that emerges in the midst of the pandemic. Therefore, the concepts of power devices by Michel Foucault and Homo Sacer by Giorgio Agambem are used. Thus, the inseparability between the microsocial and macrosocial dimensions of the problems presented is perceived, and the term "frontline" is questioned in order to intersect the suffering of hospital service professionals with that of other health professionals in the SUS network, on medium complexity devices. It is concluded that the sacrificial dimension that the SUS health professional subjectively produces sustains a state of exception that, ultimately, by sacralizing the 'true heroes' also exposes them, both to the unnecessary risk of contagion and in the decisions to make a living and let it die.

Keywords: Worker'shealth; Mental health; Pandemic; Remotework.

Os tensionamentos produzidos pela (im)possibilidade de trabalho remoto na atual pandemia do COVID 19 em um CAPS torna-se um analisador pertinente, visto que há diversos estudos (Horta et al., 2021; Zhan et al., 2020) analisando especificamente as implicações de trabalhadores que estão na linha de frente (UTI COVID) sem que haja a inclusão do processo de trabalho da atenção de média complexidade enquanto parte dos efeitos deletérios produzidos acerca do descaso e invisibilidade dos trabalhadores pelo Estado.

Desse modo, o relato de experiência de duas trabalhadoras de saúde mental em um CAPS I de um município do Sul do Brasil de médio porte reflete as implicações nas relações de poder entre trabalhadores da saúde mental e gestão do município, situadas entre os meses de junho de 2020 há março de 2021. Conforme Daltro e Faria (2019), a abordagem de relato de experiência profissional performatiza através

multiprofissional que reúne médicos, assistentes sociais, psicólogos, psiquiatras, entre outros especialistas. Propiciam acolhimento e acompanhamento à saúde mental para dar suporte à travessia que o outro deve construir em sua experiência. Além disso, os profissionais atuam na discussão de casos em equipe, psicoterapias, atendimento às crises, elaboração de planos individuais de cuidado, grupos e oficinas. (Conselho Federal de Psicologia [CFP], 2013). 
da linguagem a experiência do um, não enquanto centralidade estável, mas na condição de ponto de abertura e análise crítica para a pluralidade de narrativas. Sendo que a experiência ocorre em simultaneidade a ideias e acontecimentos, nossas reflexões partem de um sujeito que está "sendo" a partir de um determinado tempo e espaço, o que nos permite dizer que nossas reflexões não são neutras, pois somos sujeitos implicados nessa instituição analisada. Para Macedo (2016), a pesquisa é "acontecimento", compreendida a partir de duas perspectivas: primeiro, como inseparável da subjetividade; segundo, como promotora do que chama de "memória incorporada" em um corpo que simultaneamente cria e é habitado pela experiência.

Apesar do contágio comunitário entre mais da metade de trabalhadores (16 profissionais de saúde para uma equipe de 25 profissionais, incluindo estagiários de psicologia, estagiário da recepção, profissionais administrativos, vigilante e equipe técnica) e indicadores de morbi-mortalidade municipais e estaduais, foram impedidas pela gestão municipal as decisões de proteção aos profissionais de saúde mental bem como as estratégias de trabalho remoto, especialmente em home office, no período denominado de "bandeira preta".

Neste artigo, optamos por manter o mais restrito possível informações acerca do município, com vistas a possibilitar o sigilo acerca da instituição. A escolha de um olhar localizado para um ampliado relativo ao lócus de análise refere-se ao campo de afecções dessa experiência, de tal modo que relatá-la se tornou o meio e o fim para se apropriar dela. Quando discorremos sobre uma realidade, está implícita a força e a forma das relações de poder e das possibilidades múltiplas de representá-la.

Desse modo, o relato sobre a impossibilidade de trabalho remoto $\mathrm{e}$ as implicações subjetivas mobilizadas pôde, de fato, ser problematizada quando pudemos "nos afastar da ilha para ver a ilha, não nos vemos se não saímos de nós" (Saramago, 1998). Eis que emerge o cenário ético-político brasileiro. "Tudo é político, pois se alguma relação de força é desviada do sistema de governo ela é política por ser desviante, caso contrário ela também é política, posto que ela confirma o sistema." (Trindade, \& Galli, 2009, p. 236)

Discursos são práticas; práticas são discursivas (Foucault, 1995). Justificativas como "estamos em guerra" e "quem é da saúde deve se sacrificar" produz endereçamentos analíticos para além deste acontecimento e complementares aos estudos em saúde coletiva.

Para além da produção do núcleo de saber ${ }^{3}$ da Psicologia, especificamente sobre as Resoluções do Conselho Federal de Psicologia Resolução 11/2018 e 04/2020, voltadas à relevância do atendimento remoto em saúde mental em tempos de pandemia, a análise da saúde coletiva enquanto campo de saber interdisciplinar nos permitiu através do nosso contexto local, problematizar a construção subjetiva sacrificial direcionada aos profissionais de saúde em tempos de COVID 19 que perpassam de maneira mais ou menos invasiva trabalhadores de distintas áreas de atuação no setor saúde.

A gramática bélica como "guerra contra COVID 19", "linha de frente" serão melhores trabalhadas pela perspectiva teórica relacionada às ciências sociais sobre as tecnologias de poder Foucault (2004) e Homo Sacer, presentes em Giorgio Agamben (2003; 2004) e serão utilizadas, juntamente com os autores brasileiros Lobo (2020), Bastos et al. (2020), Pieper, Miguel e Mendes (2020), Moreira, Sousa, e Nóbrega (2020) que retomam tais conceitos na análise dos discursos de governo no contexto brasileiro como "um dia todo mundo morre"; "sou Messias, mas não faço milagre". Revelando indícios de que

\footnotetext{
${ }^{3}$ Gastão Campos (2007) sugere os conceitos de Campo e Núcleo na formação em saúde. Núcleo seria o conjunto de saberes e de responsabilidades específicas a cada profissão ou especialidade. Por Campo seriam os saberes e responsabilidades comuns ou confluentes a várias profissões ou especialidades.
} 
pandemia não é somente questão de saúde pública, mas envolve principalmente o campo da política. Política em dois sentidos: como afirma Lobo (2020). Tanto como tomadas de decisões que afetam nossas vidas, como aquela concepção de política enquanto o colocar-se na pólis.

Ou seja, o aparente conservadorismo e rigidez nas adaptações ao uso de tecnologias no cuidado em saúde, é parte ínfima de uma fotografia maior: do ponto de vista das ações na área de saúde, as respostas das autoridades políticas de diversos países têm sido marcadas por incertezas ou mesmo descaso. Esses posicionamentos que vão da gestão local às decisões do governo nacional, imperam em uma racionalidade negacionista, predispondo a população ao adoecimento e/ou à morte. Ao sacralizar os profissionais de saúde, também lhes expõem ao sacrifício divino (soberano) de contágio e adoecimento e em último caso, específico aos profissionais em serviços hospitalares, a escolher quem pode morrer, relegando o sujeito a negar a própria finitude e a recolher o sofrimento que seria coletivo ao âmbito íntimo.

\section{Contextualizando o trabalho em saúde mental: (im)possibilidades de atuação e proteção}

Desde junho de 2020, quando mais da metade da equipe passou a ser infectada, alguns profissionais de saúde sentiram-se mobilizados, seja por possuírem doenças crônicas, idade superior a 60 anos, seja pelo medo de contaminar familiares que apresentavam tais condições de saúde. Durante esse tempo, percebíamos o sofrimento psicossocial referente ao medo de exposição a situações de risco. A mudança das relações de trabalho em saúde depende principalmente da produção de saúde que se dá na micropolítica da organização do trabalho, no âmbito das relações, nos vínculos entre os diferentes atores (Moreira, Sousa, \& Nóbrega, 2020). No entanto, muitos de nós apresentavam sintomas de ansiedade, depressão e doenças psicossomáticas sem que houvesse abertura em quaisquer momentos, incluindo as reuniões semanais, para se falar abertamente sobre a saúde mental da equipe. Este adoecimento da equipe pôde ser percebido através de inúmeros afastamentos e atestados referindo tais sintomas, impossibilitando assim alguns atendimentos à população, devido ao desfalque da equipe que compunha o CAPS.

No ínterim de mais de um ano de pandemia, com exceção da suspensão de grupos terapêuticos, todas as atividades permaneceram presenciais. Houve a implantação do "plantão em saúde mental", em que fora disponibilizado diariamente, em horário comercial, a escuta inicial das demandas e necessidades de cuidado em saúde mental através do atendimento por telefone. Nessa primeira escuta telefônica, conforme a demanda da população, era comum o acolhimento de pessoas que ligavam por sintomas associados à depressão, ansiedade e uso de drogas. O objetivo dessa estratégia era, sobretudo, ofertar a cada usuário de saúde de acordo com seu sofrimento emocional, os encaminhamentos necessários enquanto porta de entrada ao CAPS.

Apesar da experiência do plantão em saúde mental ser avaliada pelos trabalhadores como efetiva, bem como as reuniões de equipe em modalidade online ser adotadas como parte do processo de trabalho, após contágio de grande parte dos trabalhadores, houve diversas resistências de um fazer saúde que agregasse posicionamento ético-políticos em que o cuidado de si (equipe) e cuidado do outro (usuários de saúde) fossem questões indissociáveis em tempos de pandemia. Associado a esse panorama, houve processos de culpabilização dirigido aos profissionais da equipe que reivindicaram o uso da ferramenta online de atendimento, pela gestão de saúde municipal e a estratégia de revezamento com o atendimento presencial. Discursos como "profissional de saúde fez uma escolha", "estamos numa guerra" ou "devemos esquecer nossas questões pessoais em benefício da população", estes profissionais eram associados à vagabundagem ou impertinência pelos gestores ou até mesmo por parte da equipe. 
Ser ou não ser linha de frente de uma guerra contra o COVID 19, fora o principal argumento utilizado por parte de alguns atores sociais implicados que sustentavam a exclusividade de manutenção do atendimento presencial, de um fazer saúde na atenção a transtornos mentais severos e persistentes. Todavia, ao ser reivindicado o direito dos trabalhadores a adicional por insalubridade e o direito ao teste rápido para COVID 19, como acompanhamento das equipes de saúde, o antagonismo se fazia presente: não éramos mais considerados pela gestão como sendo "linha de frente". Ser ou não ser, eis a questão de um processo de subjetivação que desautorizava o trabalhador de questionar suas problemáticas, bem como invalidando a possibilidade de trabalho remoto, especialmente nos meses considerados em "bandeira preta" pelo governo estadual.

Diversas experiências exitosas ${ }^{4}$ foram relatadas em estudos acerca do atendimento em saúde mental em modalidade remota. Escolhemos pelo documento que embasou nossos esforços em possibilitar a reflexão sobre nossas práticas em saúde mental. Enquanto um modelo de inspiração e organização que incluísse toda a equipe multiprofissional, nos baseamos na Resolução n ${ }^{\circ} 04 / 2020$ do Conselho Federal de Psicologia (Resolução n. 4,2020 ) que permite o atendimento psicológico online em situações de emergência. Nessa seara, a Fiocruz (Noal, Passos \& Freitas, 2020) lança um caderno específico com orientações aos profissionais de saúde, apresentando a modalidade de atendimento psicossocial remoto como vantajoso, uma vez que corrobora

\footnotetext{
${ }^{4} \mathrm{O}$ cuidado em saúde remoto foi relatado como exitoso em outros serviços de saúde mental nacionais e internacionais. Cruz et al, 2020; Kavoor, Chakravarthy, \& John., (2020); Schmidt, Crepaldi, Bolze, Neiva-Silva, $\&$ Demenech (2020) e Yellow leeset al., 2020), relatam a implementação do serviço da telemedicinacomo exitosa em serviços de saúde mental na Austrália, como medida sanitária de reduzir a circulação e propagação do contagio da COVID-19. Em outro estudo australiano Looi, Allison, Bastiampillai, \& Pring, (2020), analisaram a implementação do trabalho remoto em saúde mental na rede estadual como bem aceita pela comunidade. No cenário brasileiro Cruz et al., (2020) relatam os atendimentos dos CAPS dos municípios de Ilhéus e
}

com as orientações de distanciamento social, quarentena e/ou isolamento domiciliar. Nesse sentido é possível ofertar atendimento psicológico de qualidade (Noal, Passos, \& de Freitas, 2020). Estávamos determinadas a demonstrar as contingências que sustentariam esta estratégia de cuidado em saúde mental, possibilitando o revezamento entre ações de cuidado presenciais com modalidades não presenciais em momento de recrudescimento da pandemia. São elas:

1) Os altos índices de morbimortalidade por COVID 19 no Rio Grande do Sul, refletemse tanto na população de usuários de saúde como na equipe (como supracitado).

2) Metade da equipe residia em outras cidades. Alguns profissionais deslocavam-se de ônibus intermunicipal, muitas vezes com $100 \%$ de lotação;

3) Uma entre quatro estagiárias de psicologia que fora infectada por COVID 19, recebeu orientação médica de que não poderia retornar às suas atividades presenciais devido às sequelas causadas pelo adoecimento. A partir da mobilização de um dos supervisores de estágio as práticas de formação passaram a ocorrer em modalidade online ${ }^{5}$. A implantação do estágio nessa modalidade passou a incluir atendimentos clínicos individuais, seminários e supervisões, estratégia que em parte poderia ser estendida aos demais profissionais do CAPS;

No entanto, se o trabalho online demonstrava benefícios no trabalho terapêutico aos que possuíam indicação e acesso à tecnologia, quais foram às condições da

Itabuna, os quais estavam com altas prevalências do número de casos da COVID-19. Nestes locais foi criado um grupo de WhatsApp para usuários do CAPS. A premissa da formação do grupo era informação sobre as atividades do serviço e encaminhamentos, bem como a realização de grupos terapêuticos online tendo em vista os efeitos do isolamento social na saúde mental. No estado de Goiás (Kadri\& Cunha, 2020), foi implantado sistema de atendimento online em 78 CAPS da região.

5 Esta temática foi objeto de estudo publicado por supervisora e estagiárias em livro específico sobre as práticas de atenção em saúde em tempos de pandemia. Reserva-se nesse momento informações adicionais desse estudo com vistas a preservar a avaliação às cegas. 
impossibilidade na utilização transitória desta estratégia de cuidado em saúde? Essa questão nos levou a problematizações de um cenário mais ampliado que atinge a todos os trabalhadores de saúde em diversos níveis de atenção em saúde. A amálgama entre omissão da saúde da população por parte do Estado e a invalidação do cuidado à saúde do trabalhador em contextos de COVID 19.

\section{Linha de frente: metáforas bélicas}

Mortes e contágios, as cenas de covas e caixões já não causam espanto e comoção. Hoje é 27 de março de 2021, o COVID 19 já contabilizou 3.650 vítimas fatais, recorde no país desde o começo da pandemia, em março de 2020, totalizando 310.550 mortos pela COVID19 e 12.490 .362 de contaminados, de acordo com dados do Conselho Nacional de Secretários de Saúde (CONASS ${ }^{6}$, 2021). Estudiosos (Ferreira \& Porto, 2019; Siqueira, Ferreira, \& Andrade, 2020) no campo da bioética tem sublinhado a Mistanásia como uma produção de morte miserável antes e fora do seu tempo, de agravos em saúde que seriam evitáveis, se não fosse a combinação pobreza omissão social, facilitadora de morbidade e doenças (Cabral \& Zaganelli, 2016; Siqueira et al., 2020).

A pandemia tem colocado em evidência as profundas desigualdades socioeconômicas e territoriais (Lobo, 2020). Para muitos sujeitos reside uma não-escolha: morrer de fome ou de coronavírus?

Precisamos
da desregulamentação do trabalho,
que levou as pessoas negras,
principalmente mulheres e jovens, a
uma situação muito complicada de
trabalho informal, em que, se elas não
trabalham, não recebem. Então, hoje,
falar para essa pessoa parar de
trabalhar e ficar em casa significa
condená-la a ficar sem comer. (Santos
et al., 2020)

Precisamos lembrar da que levou as pessoas negras, principalmente mulheres e jovens, a uma situação muito complicada de trabalho informal, em que, se elas não trabalham, não recebem. Então, hoje, falar para essa pessoa parar de trabalhar e ficar em casa significa et al., 2020)
Complementar a essa dimensão, as pesquisas de Esperidião, Saidel e Rodrigues (2020) e Prado, Peixoto, Da Silva e Scalia (2020) associam o sofrimento em saúde mental aos profissionais hospitalares de cuidados intensivos. Destacam-se as condições laborais: sobrecarga de trabalho; equipamentos; suporte organizacional escasso; política frágil de cargos e salários; inexistência de piso salarial da categoria; elevada carga de trabalho; baixa remuneração; duplos vínculos empregatícios e precários; responsabilidade elevada; lida cotidiana com a dor, sofrimento, morte.

A expressão "herói" produz efeitos contraditórios uma vez que o heroísmo retira as características humanas de vulnerabilidade, temor e reflexividade. O herói não pensa, age impulsionado pela crença na indestrutibilidade e desejo de salvar o outro. Ele não precisa ser remunerado adequadamente, afinal age por idealismo (Fortuna, 2020). Trata-se de problematizar a dimensão sacrificial de profissionais de saúde posicionados como "verdadeiros heróis" que ao serem lançados em "linhas de frente", em ações e serviços de saúde deteriorados pelo desinvestimento nos sentidos econômicos e sociais, devem cumprir seu ideal messiânico de salvar vidas; são ferramentas de poder do Estado que se exime de suas responsabilidades ao evitar enxergar e reconhecer a morte a olho nu. Ao reiterar-se a produção discursiva de "um estado de guerra", os profissionais de saúde devem exceder a norma para decidir quem deve viver ou morrer (nos casos de sistemas de alta complexidade hospitalares e de emergência).

Concomitantemente, frente à insuficiência dos sistemas de saúde, lentidão no processo de vacinação, do número de leitos, dos equipamentos de diagnóstico e tratamento da doença, sobretudo em seus casos mais graves, surge o dilema em torno da decisão sobre quem vive ou é deixado a morrer, fazendo operar de forma radical o princípio do que Foucault (1999; 2007) chamou de biopolítica. Em seu sentido mais antigo a biopolítica compreende o conjunto de dispositivos de regulação da

\footnotetext{
${ }^{6}$ https://www.conass.org.br/painelconasscovid19
} 
sociedade, da saúde pública ao bem-estar infantil, implicados na manutenção da ordem e no controle da moral: esse projeto utópico de normalização da vida inicialmente imaginado a partir do século XVIII (Han, 2018).

Em meio a um regime de biopoder (poder sobre a vida) não se poderia exercer o velho direito soberano de matar - expor à morte, ou multiplicar para alguns o risco de morte; decretar publicamente à morte política, a expulsão, a rejeição (Birman \& Seixas, 2012). No entanto, serviços de saúde brasileiros vivem uma enxurrada de situações extremas, em práticas de exceção que se confundem com um estado de "guerra civil legal". (Luiz, 2016). A absolutização sem precedentes do biopoder se conjuga com a generalização do poder soberano e a biopolítica se confunde necessariamente com uma thanatopolítica. Diante disso, Agamben (2003) propõe uma terceira fórmula que apreenderia a especificidade da biopolítica do século $\mathrm{XX}$ : "não mais fazer morrer, nem fazer viver, mas fazer sobreviver" (Agamben, 2003, p.108). Nem vida, nem morte, mas apenas produção de sobrevida.

A guerra é contra um vírus mortal, como se a natureza não fosse mediada pelos processos sociais implantados em sua dominação e exploração (Zamora, 2020). A imagem bélica reforça a militarização das decisões políticas em relação à crise sanitária dando poder da possibilidade de declaração de guerra e de expor a perigo e sacrificar vidas humanas, ou seja, a sujeição a um poder político ilimitado e arbitrário (Schimidt, 2020). Assim, a guerra é fazer política por outros meios. Sobretudo, invocar o velho direito soberano à morte é uma questão da biopolítica ${ }^{7}$ que foi retomada pela análise deste autor sobre o homo sacer ${ }^{8}$ e a vida nua.

7 De acordo com Agamben (2003), o ponto no qual esses dois aspectos do poder (soberania-biopolítica) convergem não teria sido esclarecido pelo pensamento foucaultiano, permanecendo como um "ponto oculto" ou "uma zona de indeterminação".
No que consiste a vida nua, a primeira aproximação feita por Agamben (2003) foi por meio da distinção realizada pelos gregos entre zoé e bíos. Ressalta o pensador que tais termos eram utilizados para designar porções diversas do que é simplesmente compreendido como "vida". Enquanto zoé reportava-se ao simples fato de viver (fato este idêntico a todos os seres vivos, sejam homens ou qualquer outro animal), bíos é o nome atribuído a uma maneira específica de se viver, característica de um simples indivíduo ou de uma coletividade - em outras palavras, a bíos simboliza "uma vida qualificada, um modo particular de vida" (Agamben, 2003, p. 9). Se no mundo clássico o espaço político é ocupado somente pela bíos (vida qualificada), na modernidade ele inclui em seu funcionamento a zoé (vida meramente biológica) - e o corpo, despido de substância política, passa a ser alvo de absolutamente qualquer intervenção: torna-se "vida matável", "vida indigna de ser vivida", pode ser assassinada ou torturada sem que se cometa um crime. (Agamben, 2003). A vida passa então, a coincidir exatamente com o espaço político, onde exclusão e inclusão, bios e zoé, direito e fato passam a habitar uma zona de indeterminação (Arán \& Peixoto Júnior, 2007; Santos \& Pedro, 2020).

Vida nua, vida que se pode deixar morrer; estando fora da jurisdição, a 'vida nua' é a vida que pode ser exterminada sem que se cometa qualquer crime ou sacrifício. A vida nua seria a portadora do nexo entre violência e direito. Assim, a sacralidade da vida hoje significa a "sujeição da vida a um poder de morte". A exposição à morte dessas vidas que não importam não é classificável nem como sacrifício e nem como homicídio. Subtraindose às formas sancionadas dos direitos humanos e divino. (Agamben, 2004; Rosa, 2007)

Para Agamben (2004, p. 90) o homo sacer é uma figura desprovida de direitos, um ser

8 Numa figura enigmática do direito romano arcaico, Agamben (2003, p. 91) buscou o conceito de homo sacer- pessoa que foi posta para fora da jurisdição humana - sem, entretanto, ultrapassar para a esfera divina. 
excluído da sociedade que pode ser morto impunemente, mas não pode jamais ser sacrificado aos deuses. A sacralidade da vida não é, como se pode pensar, um direito humano inalienável e fundamental, na modernidade ela é destituída da ideia do sacrifício. O homo sacer não faz parte da vida a ser preservada, mas sim da vida descartável, compondo a estrutura de exceção contemporânea. (Rosa, 2007, p. 5).

Revelando a ambiguidade entre sacralização e sacrifício dos discursos acerca da profissão saúde, em especial em tempo pandêmicos, tem ocorrido à convocação de diversos Estados do país pelo trabalho voluntario, em um contexto onde tecnologias de fazer viver como oxigênio, respiradores e outros artefatos estão marcadamente esgotados. $\mathrm{O}$ que esses profissionais poderiam ao serem destituídos de suas tecnologias da biomedicina a não ser dar a extrema-unção ${ }^{9}$ ? Quando a saúde e suas tecnologias de salvar vidas substituem a salvação da alma, conclui Foucault (2004), o poder biomédico se eleva drasticamente, no entanto voltamos à salvação anterior ao século XVIII, o hospital como instituição de caridade, um lugar para morrer (Foucault, 2007).

Enquanto profissionais de saúde mental não somos "os verdadeiros heróis"; a figura sacralizada do poder médico é convocada a exercer o poder divino de vida e morte enquanto sacrifica sua própria alma. No entanto, algumas problemáticas apresentados pelo processo de trabalho em um CAPS revelaram que em tantos outros serviços do SUS de baixa e média complexidade, ou seja, para além das cercanias da UTI, as práticas de cuidado em saúde se deram em um contexto desnecessário de exposição ao COVID 19 tanto quanto de usuários como de trabalhadores de saúde. A resistência, no caso relatado, às medidas de atenção em saúde mental em modalidade online, não diz respeito apenas ao

\footnotetext{
9 Extrema-unção: Um dos sete sacramentos da Igreja católica, que consiste na unção com óleos santos os moribundos ou pessoas que estão prestes a morrer. Também depende do profissional de saúde alocado em
}

engessamento da absorção de novas tecnologias de cuidado no fazer saúde, mas, sobretudo a uma lógica governamental que invalida as necessidades de saúde do trabalhador. Desse modo, para além da problemática social e contingencial apresentada, buscamos enquanto parte da análise de implicação, apresentar, através de um panorama epistemológico autores pósestruturalistas como Foucault (1999; 2004; 2007) e Agamben (2003; 2004) para refletirmos sobre essa construção subjetiva do profissional de saúde através de discursos bélicos, fomentadora de certas práticas e modos legitimados de se posicionar diante do cuidado em saúde mental.

\section{Considerações Finais}

O presente artigo através de relato de experiência de duas profissionais de saúde em um CAPS de município de médio porte do Rio Grande do Sul retratou as angústias e os tensionamentos acerca das profissionais de saúde mental em relação aos modelos de atenção em saúde mental adotados, especificamente sobre as resistências do trabalho remoto em contexto de expressiva transmissão comunitária de COVID 19 na equipe de trabalho analisada. $O$ relato de experiência enquanto metodologia de análise colocou às autoras o desafio de articular teoricamente conhecimentos que marcam seu pertencimento coletivo, ao mesmo tempo em que ativam suas competências de tradução, percepção e interpretação. Com isso, para conhecer, importa o gesto inventivo afirmando o um, não mais enquanto operador neutro, mas atuante e atravessado de forma relacional, que age e interage, abrindo-se para se afirmar como particularidade. Poder descrever um contexto e suas implicações na prática em saúde, que possa também visibilizar a saúde mental destes profissionais, que mesmo não estando "no combate" de um front, entendido a atenção em

serviços de urgência e de nível terciário em saúde (hospitais) ofertar (ou não) algumas estratégias de comunicação entre usuários de saúde internados e familiares, bem como a comunicação de más notícias aos familiares. 
alta complexidade, que compulsoriamente decide por vida e morte estão ainda assim estão expostos ao adoecimento resultante das relações do processo de trabalho, e determinadas condições de risco que não são sanadas, como por exemplo, o envio do número correto de EPIs que contemplem todos os profissionais atuantes no CAPS.

Esta temática apresenta-se como relevante ao analisamos as relações de poder no campo da biopolítica brasileira, tanto no contexto microssocial como macrossocial. Percebemos as condições de (im) posssibilidade de cuidado à saúde do trabalhador da saúde, que ao passo que é incumbido ao discurso do profissional como herói (diante de certas apropriações de um modo de fazer saúde) é capturado subjetivamente em direção à noção de sacrifício como parte de sua obrigação e zelo pela profissão. Reivindicar estratégias de cuidado ao trabalhador torna-se, assim, fonte de estigma no processo de trabalho, mas também de resistência, nesse caso através da escrita de experiência localmente situada enquanto endereçamentos que denunciam circunstâncias de um estado de exceção que atinge tanto usuários de saúde como trabalhadores em todos os níveis de atenção em saúde.

\section{Referências}

Agamben, G. (2003). Homo sacer: o poder soberano e a vida nua. São Paulo, Iluminuras.

Agamben, G. (2004). Estado de exceção.:[Homo Sacer, II, I]. Boitempo Editorial.

Arán, M., \& Peixoto Júnior, C. A. (2007). Vulnerabilidade e vida nua: bioética e biopolítica na atualidade. Revista de Saúde Pública, 41(5), 849-857. doi: 10.1590/s0034-89102006005000038

Bastos, M. A. P. C., da Silva, R. F., da Silva, E. A., Bastos, N. C. C., Cavalcanti, A. C. T., \& Cavalcanti, E. C. T. (2020). O Estado de Exceção nas Favelas: perspectivas biopoliticas a partir da pandemia do covid19. Revista Augustus, 25(51), 113-129. doi: 10.15202/1981896.2020v25n51p113

Cabral, H. L. T. B., \& Zaganelli, M. V. (2016). Mistanásia: a morte miserável. São Paulo: Brasil Multicultural.

Campos, G. W. S. (2007). Um método para análise e co-gestão de coletivos: a constituição do sujeito, a produção de valor de uso e a democracia em instituições: o método da roda. São Paulo: Huncitec.

Conselho Federal de Psicologia [CFP]. (2013). Referências Técnicas para Atuação de Psicólogas(os) no CAPS - Centro de Atenção Psicossocial. Brasília: CFP. Recuperado de https://site.cfp.org.br/publicacao/referencias -tecnicas-para-atuacao-de-psicologasos-nocaps-centro-de-atencao-psicossocial/

Cruz, N. M. L. V., Souza, E. B. de, Sampaio, C. S. F., Santos, A. J. M. dos, Chaves, S. V., Hora, R. N. da, ... Santos, J. E. dos. (2020). Apoio psicossocial em tempos de COVID-19: experiências de novas estratégias de gestão e ajuda mútua no sul da Bahia, Brasil. APS EM REVISTA, 2(2), 97-105. doi: 10.14295/aps.v2i2.94

Daltro, M. R, \& Faria, A. A. (2019). Relato de experiência: Uma narrativa científica na pós-modernidade. Estudos e Pesquisas em Psicologia, 19(1), 223-237. Recuperado de http://pepsic.bvsalud.org/scielo.php?script= sci_arttext\&pid=S180842812019000100013\&lng=pt\&tlng=pt.

Esperidião, E., Saidel, M. G. B., \& Rodrigues, J. (2020). Saúde mental: foco nos profissionais de saúde. Revista Brasileira de Enfermagem, 73(suppl 1). doi: 10.1590/0034-7167.202073supl01

Ferreira, S., \& Porto, D. (2019). Mistanásia $\times$ Qualidade de vida. Revista Bioética, 27(2), 191-195. doi: 10.1590/198380422019272000

Foucault, M. (1999). Microfísica do poder (14 ed.). Rio de Janeiro: Graal.

Foucault, M. (2004). Naissance de labiopolitique: CoursauCollège de France, 1978-1979. Paris, Gallimard/Seuil. 
Foucault, M. (2007). Segurança, Território, População. São Paulo: Martins Fontes

Fortuna, C. M. (2020). Nem heróis, nem novo e nem normal: a pandemia e as práticas profissionais da enfermagem. Online Brazilian Journal of Nursing (Online), 19(2). Recuperado de https://pesquisa.bvsalud.org/portal/resource /pt/biblio-1152112

Han, C. Experience: Being Policed as a Condition of Life (Chile). In D. Fassin (Ed.), Writing the World of Policing The Difference Ethnography Makes (pp. 162183). Chicago, EUA: University of Chicago Press

Horta, R. L., Camargo, E. G., Barbosa, M. L. L., Lantin, P. J. S., Sette, T. G., Lucini, T. C. G., ... Lutzky, B. A. (2021). O estresse e a saúde mental de profissionais da linha de frente da COVID-19 em hospital geral. Jornal Brasileiro de Psiquiatria, 70(1), 30-38. doi: 10.1590/0047-2085000000316

Kadri, M. R. \& Cunha, D. A. (2020). O Contexto da Pandemia e os Aspectos Éticos da Atuação da Psicologia. In Brasil (Org.), Guia de atenção psicossocial para o enfrentamento do COVID-19 no Amazonas (pp. 3-7). Brasília: Ministério da Saúde.

Recuperado de http://www.saude.am.gov.br/docs/covid19/ Arquivo_curso.pdf

Kavoor, A. R., Chakravarthy, K., \& John, T. (2020). Remote consultations in the era of COVID-19 pandemic: Preliminary experience in a regional Australian public acute mental health care setting. Asian Journal of Psychiatry, 51, 102074. doi: 10.1016/j.ajp.2020.102074

Lobo, J. C. (2020). SANTOS, Boaventura de Sousa. A cruel pedagogia do vírus (Pandemia Capital). São Paulo: Boitempo, 2020. 35p. Campos - Revista de Antropologia, 21(1), 225-228. doi: 10.5380/cra.v21i1.73566

Looi, J. C., Allison, S., Bastiampillai, T., \& Pring, W. (2020). Private practice metropolitan telepsychiatry in larger Australian states during the COVID-19 pandemic: an analysis of the first 2 months of new MBS telehealth item psychiatrist services. Australasian Psychiatry, 28(6), 644-648. doi: 10.1177/1039856220961906

Luiz, R. P. (2016). O estado de exceçao como paradigma de governo: a pessoa humana a partir de uma leitura em giorgio agambem. Colóquio de Ética, Filosofia Política E Direito, O(0). Recuperado de https://online.unisc.br/acadnet/anais/index.p $\mathrm{hp} / \mathrm{efpd} / \mathrm{article} / \mathrm{view} / 15003 / 0$

Macedo, R. S. (2016). A pesquisa e o acontecimento: compreender situações, experiências e saberes acontecimentais. Salvador: Edufba.

Moreira, W. C., Sousa, A. R. de, \& Nóbrega, M. do P. S. de S. (2020). Mental Illness in the General Population and Health Professionals During Covid-19: A Scoping Review. Texto \& Contexto -

Enfermagem, 29, e20200215. doi: 10.1590/1980-265x-tce-2020-0215

Noal, D. S., Passos M. F. D., \& de Freitas, C. M. (2020). Recomendações e orientações em saúde mental e atenção psicossocial na COVID-19. Rio de Janeiro: Fiocruz, 2020. Recuperado de https://www.fiocruzbrasilia.fiocruz.br/wpcontent/uploads/2020/10/livro_saude_ment al_covid19_Fiocruz.pdf

Prado, A. D., Peixoto, B. C., Da Silva, A. M. B., \& Scalia, L. A. M. (2020). A saúde mental dos profissionais de saúde frente à pandemia do COVID-19: uma revisão integrativa. Revista Eletrônica Acervo Saúde, (46), e4128. doi: 10.25248/reas.e4128.2020

Pieper, F., Miguel, M., \& Mendes, D. (2020). Necropolítica e sua lógica sacrificial em tempos de pandemia. Estudos Teológicos, 60(2), 533-553. doi: 10.22351/et.v60i2.4077

Resolução $n^{\circ}$ 11, 11 de maio de 2018. Regulamenta a prestação de serviços psicológicos realizados por meios de tecnologias da informação e da comunicação e revoga a Resolução CFP n ${ }^{\circ}$ 11/2012. Recuperado de https://epsi.cfp.org.br/resolucao-cfp-no-11-2018/

Resolução $n^{\circ}$ 4, de 26 de março de 2020. Dispõe sobre regulamentação de serviços 
psicológicos prestados por meio de

Tecnologia da Informação e da

Comunicação durante a pandemia do

COVID-19. Recuperado de

https://crpsp.org/legislacao/view/207

Rosa, S. O. (2007). Estado de exceção e vida nua: violencia policial em Porto Alegre entre os anos de 1960 e 1990 (Tese de Doutorado). Universidade Estadual de Campinas, Instituto de Filosofia e Ciencias Humanas, Campinas, SP, Brasil.

Recuperado de http://www.repositorio.unicamp.br/handle/ REPOSIP/280398

Santos, L. G. M., \& Pedro, R. (2020). Máscara e homem negro: entre o contágio e o racismo em um regime necropolítico. Psicologia \& Sociedade, 32, e020017. doi: 10.1590/18070310/2020v32240337

Santos, K. O. B., Fernandes, R. de C. P., Almeida, M. M. C. de, Miranda, S. S., Mise, Y. F., \& Lima, M. A. G. (2020). Trabalho, saúde e vulnerabilidade na pandemia de COVID-19. Cadernos de Saúde Pública, 36(12), e00178320. doi: 10.1590/0102-311x00178320

Saramago, J. (1998). O Conto da Ilha Desconhecida. São Paulo: Companhia das Letras.

Schmidt, B., Crepaldi, M. A., Bolze, S. D. A., Neiva-Silva, L., \& Demenech, L. M. (2020). Saúde mental e intervenções psicológicas diante da pandemia do novo coronavírus (COVID-19). Estudos de Psicologia (Campinas), 37, e20006. doi: 10.1590/1982-0275202037e200063

Seixas, C. M., \& Birman, J. (2012). O peso do patológico: biopolítica e vida nua. História, Ciências, Saúde-Manguinhos, 19(1), 1326. doi: $10.1590 / \mathrm{s} 0104-$ $\underline{59702012000100002}$
Siqueira, S. F., Ferreira, T. H. A., \& Andrade D. C. M. (2020). Mistanásia ou eutanásia social: a morta infeliz no sus e a violação do princípio da dignidade da pessoa humana. Caderno de Graduação - Ciências Humanas E Sociais - UNIT SERGIPE, 6(2), 99-112. Recuperado de https://periodicos.set.edu.br/cadernohuman as/article/view/8541

Trindade, D. D., \& Fonseca, T. M. G. (2009). Que política é possível com o pensamento deleuziano?. Revista Mal Estar e Subjetividade, 9(1), 233-249. Recuperado de

http://pepsic.bvsalud.org/scielo.php?script= sci_arttext\&pid=S151861482009000100010\&lng=pt\&tlng=pt

Yellowlees, P., Nakagawa, K., Pakyurek, M., Hanson, A., Elder, J., \& Kales, H. C. (2020). Rapid Conversion of an Outpatient Psychiatric Clinic to a $100 \%$ Virtual Telepsychiatry Clinic in Response to COVID-19. Psychiatric Service, 71, 749752. Recuperado de https://ps.psychiatryonline.org/doi/10.1176/ appi.ps.202000230

Zamora, J. C., Curia, B. G., Dupont, M. F., Marques, S. S., Luft, C. Z., Arnoud, T., ... Habigzang, L. F. (2020). Você não está sozinha! enfrentando a violência contra a mulher no isolamento pela COVID-19. Porto Alegre: PUCRS. Recuperado de http://www.pucrs.br/wpcontent/uploads/2020/05/Voce-na-estasozinha-CartilhaMulheres.pdf

Zhan, Y., Liu, Y., Liu, H., Li, M., Shen, Y., Gui, L., ... Yu, J. (2020). Factors associated with insomnia among Chinese front-line nurses fighting against COVID19 in Wuhan: A cross-sectional survey. Journal of Nursing Management, 28(7), 1525-1535. doi: 10.1111/jonm.13094 


\section{Dados sobre as autoras:}

- Helen Barbosa dos Santos: Doutora e Mestre em Psicologia Social da UFRGS pelo Núcleo de Estudos em Relações de Gênero, Sexualidade e Raça (NUPSEX).

- Fernanda Marques Paz: Mestre em Saúde Coletiva pela UNISINOS. Especialista em Terapia Familiar e de Casal. Especialista em Prevenção e Abordagem em Dependência Química.

- Fábio Dal Molin: Mestre em Psicologia Social (UFRGS). Doutorado em Sociologia (UFRGS). Pós- Doutorado em Educação (UFRGS).

\section{Declaração de Direito Autoral}

A submissão de originais para este periódico implica na transferência, pelos autores, dos direitos de publicação impressa e digital. Os direitos autorais para os artigos publicados são do autor, com direitos do periódico sobre a primeira publicação. Os autores somente poderão utilizar os mesmos resultados em outras publicações indicando claramente este periódico como o meio da publicação original. Em virtude de sermos um periódico de acesso aberto, permite-se o uso gratuito dos artigos em aplicações educacionais e científicas desde que citada a fonte conforme a licença CC-BY da Creative Commons. 